\title{
DAMAGE INVESTIGATION AND ASSESSMENT DUE TO LOW- VELOCITY IMPACT ON FLAX/GLASS HYBRID COMPOSITE PLATES
}

\author{
Antigoni K. Barouni* ${ }^{* a} \&$ Hom N. Dhakal ${ }^{\text {a }}$ \\ a Advanced Materials and Manufacturing (AMM) Research Group, School of Mechanical and \\ Design Engineering, University of Portsmouth, PO1 3DJ, UK.
}

\begin{abstract}
There is limited information available in the body of knowledge regarding to the low velocity impact damage characteristics of sustainable bio-based such as flax fibre reinforced composites. This paper presents the results of full investigation of impact damage mechanisms on flax/vinyl ester laminated composite and flax-glass/vinyl ester hybrid composite laminates caused by low-velocity impact using a drop weight impact machine. The specimens were subjected to incident energy levels of $25 \mathrm{~J}$ and $50 \mathrm{~J}$, in order to achieve a damage up to perforation and complete penetration. A 3D Finite Element Analysis (FEA) model was also developed using Hashin failure criteria. The damage and the predicted delaminations were compared using a high-resolution micro-Computed Tomography ( $\mu$-CT) technique. The results of the numerical analysis correlated well with the experiments and the imaging, which provided a full verification of the exact position of delaminations due to impact within the composite laminates.
\end{abstract}

\section{KEYWORDS}

Low-velocity impact, natural fibre composites, finite element analysis, delamination, $\mu$-CT imaging.

\section{INTRODUCTION}

There is a growing demand in high-performance industry (aerospace, aviation) for more lightweight sustainable materials, yet strong enough compared to the traditional, non-renewable composite materials that are currently being used. This demand has spread to other industrial fields such as automotive, marine, construction and energy industry, making the development of such materials even more significant. At the same time, more environmentally friendly lightweight and sustainable alternatives to the conventional non-renewable reinforcing materials are required by the industry due to consumer's pressure and government's legislation. Therefore, in recent years, the use of natural plant fibres as reinforcement in polymer composites for making low-cost ecological engineering materials has attracted considerable interest. Due to their high specific properties, low cost, low density and good biodegradability, natural fibres such as flax, hemp, jute, kenaf fibre reinforced composites have attracted significant attention for use in automotive, marine and construction industry driven by lightweighting aspirations [1,2].

Despite several advantages that natural fibre as reinforcements provide, their use in composites have some drawbacks in terms of their performance. One very important aspect of the behaviour of natural polymer composites is their response to impact and their capacity to withstand it during their service life. In order to use natural fibre composites and biocomposites in semi-structural and structural applications, it is necessary to develop a comprehensive understanding of the damage types, extension of damage and damage mechanisms that take place when they are subjected to low velocity impact. Some of the reported work has suggested that natural fibre composites are sensitive to impact loading [3]. The major drawback is their low impact strength as compared to glass fibre reinforced thermoplastic and thermoset composites $[4,5]$. However, assessing the impact resistance of a composite material is always difficult since the damage manifests itself in different forms, such as delamination at the interface, fibre breakage, matrix

* Corresponding author: A.K. Barouni, +44(0) 2392 842013, antigoni.barouni@port.ac.uk 
cracking and fibre pull outs $[6,7]$. Due to their complexity, many of their damage characteristics remain unresolved $[8,9]$.

Low energy impact of fibre reinforced composites has been the subject of many experimental and analytical investigations [10-12]. Investigation of contact laws has been also conducted using appropriate models and validated with experiments [13]. More specifically, some research works have been specifically focused on understanding the impact damage response of natural fibre composites relating to properties of fibres, matrices, fibre-matrix interfaces and fibre geometry and architecture [14-16], but this field is still at its early stages of investigation. Moreover, low velocity impact damage is always more complex to assess because, in most cases, there is little indication of the damage on the impacted surface, but there could be a significant amount of damage internally [17]. There exists a wide variety of nondestructive techniques for the assessment and identification of impact damage, which are used in order to enhance the understanding of the damage mechanisms that occur during impacting. Some examples of these techniques are ultrasound (C-scan), X-ray radiography, thermography, optical and electron microscopes.

One way to address performance drawbacks of natural fibres is by using stronger and stiffer fibres as hybrid reinforcements. There are several reported works highlighting the benefits of hybridisation of natural fibre composites with some synthetic fibres. Dhakal et al. [18] presented the effect of flax fibre epoxy composites hybridised with carbon fibres. They reported a noticeable improvement in mechanical properties and water repellence behaviour of flax/epoxy composite as a result of carbon fibre hybridisation. Almansour et al. [19] reported a significant improvement on the mode II fracture toughness behaviour of flax vinyl ester composites with basalt fibre hybridisation. Similar positive effect on the low velocity impact damage characteristics of hemp-basalt hybrid epoxy composite has been reported by Kumar et al. [20].

$\mathrm{X}$-ray computer tomography $(\mu \mathrm{CT})$ is a rapidly evolving non-destructive evaluation technique, which provides 3D images of a sample and the damage. This method has been used in many studies mainly for the characterization of composite materials [20,21], but less studies have been recorded for the impact damage and failure modes assessment in composite structures [22, 23]. To bridge this gap, this study investigated the effect of incident energy levels on three different composite laminates under low-velocity impact loading. A woven flax-fibre reinforced vinyl ester based composite, a glass-fibre reinforced vinyl ester composite and a glass fibre hybridised/flax hybrid composite were investigated under two different energy levels in order to evaluate the hybrid effects of adding the glass fibres into the flax composite on the impact damage characteristics. A numerical model using dynamic explicit analysis was developed using ABAQUS to simulate the experimental results and, ultimately, attempt to predict the behaviour of flax fibre-reinforced vinyl-ester laminates under low-velocity impact testing. Numerical results, including contact force and displacement of the composite plate subjected to impact, are calculated. The damage evolution and failure mechanisms are assessed using X-ray micro-CT technique, where various types of damage are identified and discussed.

\section{EXPERIMENTAL PROCEDURE}

\section{$2.1 \quad$ MATERIALS}

The matrix material used was vinyl ester resin (Scott-Bader Crystic VE676-03) and at 1.5\% catalyst weight was used to cure. The reinforcement was woven flax with fibre orientation $[ \pm 45]_{3 \mathrm{~s}}$ biaxial stitched non-crimp fabrics of $600 \mathrm{~g} / \mathrm{m}^{2}$ in aerial weight, supplied by Net Composites Ltd. The average of fibre volume fraction (FVF) for FVE, GVE and FGVE was approximately 44.9\%, 59.7\% and 49.9\%, respectively. The void content was about $4 \%$ and was calculated in accordance with ASTM D2734-94. 


\subsection{SAMPLE FABRICATION}

Three types of composite laminates were prepared namely: Flax fibre reinforced vinyl ester (FVE), glass fibre reinforced vinyl ester (GVE) and flax fibre hybridised glass fibre hybrid (FGVE) composite laminates were fabricated using vacuum infusion process. The fabric configuration was 6 layers of $+/-45^{\circ}$ fabrics of glass and flax (Figure 1d), with laminate thickness equal to $3 \mathrm{~mm}$ and $6 \mathrm{~mm}$ respectively. The hybrid specimens were manufactured using 7 layers of $G / F / G / F / G / F / G$ configuration, where $G$ stands for glass and F for flax (Figure 1e), with $4.5 \mathrm{~mm}$ laminate thickness. The primary focus of this study was to maintain the same number of layers for the flax fibre and the glass fibre reinforced laminates. Although this results in different thickness for the final laminates, due to the structure of the flax and glass fabrics, however, the effect of the number of layers was of primary interest. In the hybrid specimens, the requirement of the glass layer of the top and bottom surface of the laminate was of great importance, due to the impact properties of the material, therefore this explains the difference in the number of layers. After infusion, the laminates were left to cure for 24 hours at room temperature before being demoulded. For optimum properties, the laminate was then post-cured for 3 hours at $100^{\circ} \mathrm{C}$. The full range of specimens and fibre sequence information are shown in Figure 1.

\subsection{INSTRUMENTAL FALLING WEIGHT IMPACT TEST}

A low velocity instrumental falling weight impact tests were employed with a hemispherical nose impact up with a diameter of $19 \mathrm{~mm}$ fitted in the impactor of total impact mass of $23.11 \mathrm{~kg}$. Two different values for the release height of the impact mass were used, at $110 \mathrm{~mm}$ and at $221 \mathrm{~mm}$. These release height values in combination with the impact mass of $23.11 \mathrm{~kg}$ provided total impact energies of $25 \mathrm{~J}$ and $50 \mathrm{~J}$ respectively at striking velocities of $1.469 \mathrm{~m} / \mathrm{s}$ and $2.082 \mathrm{~m} / \mathrm{s}$ respectively. These two incident energies were chosen to create damage up to perforation (partially broken, projectile not penetrating the specimen) and penetration (fully broken, projectile going through the specimen). These two scenarios were chosen to compare the perforation and penetration performance of composites investigated. Square specimens of dimensions $60 \times 60 \mathrm{~mm}$ were cut from the composite laminate using a diamond-cutting wheel. The specimens were firmly fixed at all edges using annular clamps with inner and outer diameters of 50 and 75 $\mathrm{mm}$ respectively and were impacted producing damage up to perforation. The test was conducted in accordance with the British Standard BSEN ISO 6603-2 recommendations [25]. A Zwick/Roell impact test machine (IFW 413) was used for the test and the drop-tower arrangement is shown in Fig. 2. During the impact in this system, the resistive force exerted by the specimen in the striker was measured by a load shell as a function of time and stored in a computer for subsequent display and analysis. From the typical force-time information, the software calculated important parameters such as load-displacement, absorbed energy and velocity, which were used to characterise the impact damage behaviour.

\subsection{IMPACT DAMAGE CHARACTERISATION}

The impacted specimens were imaged using micro-CT (micro-Computed Tomography) on a Zeiss Xradia 520 Versa system. The micro-CT scanner was set to a voltage of $80 \mathrm{kV}$ ( $60 \mathrm{kV}$ for flax only specimens) and a power of $6 \mathrm{~W}$ (4 W for flax only specimens), while a source filter was used during the imaging process (Zeiss LE1 filter) and a flat panel detector. With a voxel size of $61.61 \mu \mathrm{m}$ and an exposure time of $0.378 \mathrm{sec}(0.6 \mathrm{sec}$ for flax only specimens), the image acquisition was performed at a rotational step of $0.18^{\circ}$ over $360^{\circ}$ for $90 \mathrm{~min}$ approximately. The $3 \mathrm{D}$ reconstruction of the specimens was obtained using the Scout and Scan Control Reconstruction software, which was part of Zeiss system.

The specimens were also surface prepared and the damaged area was imaged using a Scanning Electron Microscope (SEM) on a Zeiss EVO MA10 system. The imaging was set at various magnifications starting from $\mathrm{x} 50$ up to $\mathrm{x} 500$, in order to be able to identify the damage mechanisms taking place. 


\section{FINITE ELEMENT MODELING}

A finite element model was developed in order to simulate the impact test and the damage initiation in the flax/VE composite plates. For this purpose, a square plate of woven flax fibre-VE, impacted at its centre by a cylindrical impactor $(\mathrm{R}=19 \mathrm{~mm})$ with a hemi-spherical nose, was considered. The impactor was modelled as a discrete rigid body by using 4536 R3D4 (linear quadrilateral) elements. The plate was meshed using 7140 SC8R (8-node continuous shell) elements. The mass of the impactor was modelled as an inertia around its centre of mass. The mechanical properties of the plates that were used for the simulation are given in Table 1. The finite element model of the plate and the impactor is shown in Figure 3.

The impact simulations on the flax fibre reinforced vinyl ester were conducted using the commercial software Abaqus ${ }^{\circledR}$ and implementing the Dynamic explicit solver. The plastic behaviour of the matrix and the fibre failure were modelled using the Hashin failure criterion (Hashin, 1980), which relates failure of fibres and matrix and involves four failure modes. The contact between the rigid impactor and the composite plate was modelled with a friction coefficient of 0.3 (28). The impact condition was simulated by a loading velocity applied to the centre of mass of the impactor.

\section{RESULTS AND DISCUSSION}

Three specimens were tested in each material category and each impact energy. The average values of the impact test results for both the glass, flax and glass/flax reinforced composites are presented in the forms of load vs. time, load vs. displacement and energy vs. time.

Load-time curves resulting from the impact testing are shown in Figure 4 for the two different impact energies. The load indicates the resistance offered by the specimen during the impact event. It can be observed that the peak contact force is higher for the hybrid glass/flax composite than that of flax/VE without hybridised composite, which indicates that the hybrid specimens offer higher resistance during impact. Furthermore, the hybrid composite exhibits similar peak contact force to the glass fibre reinforced composite, especially for the $25 \mathrm{~J}$ impact energy. For the energy level of $25 \mathrm{~J}$, the flax specimens exhibited a prolonged plateau of energy absorption, partially attributed to the fact that the samples were close to penetration, but also indicating an improved impact performance, whereas for the higher energy level of $50 \mathrm{~J}$ this plateau is significantly shorter in time until the specimen exhibits perforation, when the curve starts decreasing. However, in terms of strength and stiffness, it is far lower compared to the glass/VE and glass/flax VE specimen. Although they behaved better in terms of the energy absorption compared to the other two specimens, however they exhibited a lot less load bearing capability. With hybrid system, the flax/VE composite exhibited improved strength and stiffness while maintaining overall a low density. Therefore, this was the main reason why the hybridisation approach was introduced. When damage initiates and reaches its peak value, the flax impacted specimens are seen to be bearing impact load and absorbing energy. As the damage continues to propagate beyond the peak load, the flax reinforced specimens still seem to absorb energy until the specimens finally perforate, while the extent of perforation for glass/flax specimens was less at $25 \mathrm{~J}$. The time taken for damage initiation and perforation (or loss of contact between the specimen and the impactor) is shorter for the glass/flax specimens than for the flax specimens. Moreover, since the glass/flax specimens did not penetrate under the $25 \mathrm{~J}$ of impact energy. This is an indication of hybrid effects as hybrid composites exhibited much higher preformation and penetration resistance than the flax composite without hybridisation. This is attributed to the laminate structures and strength of reinforcements. The time elapsed between damage initiation and perforation remains similar to that of the glass fibre specimen at approximately $5.6 \mathrm{msec}$. However, the hybrid specimens exhibited a rebounding stage under the $50 \mathrm{~J}$, therefore the time difference between damage initiation and rebounidng is increased for the higher energy to $8.11 \mathrm{msec}$. For the flax specimens this time is much greater at $50 \mathrm{~J}$. 
The load-displacement behaviour of the impacted specimens at $25 \mathrm{~J}$ and $50 \mathrm{~J}$ is presented in Figure 5 . The initial vertical rise of the curve in the load-displacement curve correlates to the load bearing capabilities of the test specimen and demonstrates the maximum load under which the specimens can withstand the impact event without deforming for both energy levels. It is evident from this figure that the hybrid specimens exhibit improved load bearing capabilities compared to the flax only specimens for each energy, which relates to the greater resistance of the glass/flax composites to the impact event. The compatibility between the glass and flax fibres in the hybrid specimens seems to be at an acceptable level, otherwise the results for the hybrid case would not have resembled the glass/fibre case in such a good way. The load transfer mechanism, where the load is transferred to all the fibres, proves to be adequate and robust enough, to withstand these impact energy levels. Moreover, it is worth mentioning that the flax/VE specimens demonstrate zero displacement for a load equal to $0.543 \mathrm{kN}$ in the $50 \mathrm{~J}$ compared to $1.14 \mathrm{kN}$ for the $25 \mathrm{~J}$, which is a clear indication that the higher energy impact events cannot be withstood well by the flax only reinforced VE plates. Then, the stiffness of the curve changes, indicating structural degradation. The maximum value of impact load, where failure of the specimen begins, is higher for the glass and glass/flax specimens than for the flax specimens. It is also evident that the maximum deformation of the flax specimens, after the impact load is released, is higher compared to the deformation of both the glass and glass/flax specimens. This is related to the fact that the flax specimens perforated at both impact energies, whereas the extent of damage for glass specimens was lower compared to flax specimens. Similarly, the hybrid glass/flax specimens did perforate at the $50 \mathrm{~J}$ energy, which is shown by the shift of the red curve to higher displacement for the Fig. 5(b). It is evident from the results that hybrid system provided somewhat an intermediate set of properties between flax and glass fibre reinforced composites.

Impact damage in composite materials involves different fracture modes. Figure 6 shows the variations in energy absorbed by the test specimens. Both for the $25 \mathrm{~J}$ and $50 \mathrm{~J}$ of impact energies, the flax specimens absorb as much as the available energy, whereas the glass and the glass/flax specimens seem to absorb less energy, due to the rebounding stage, although some rebound is also observed for the flax specimens even if it is limited. It is clearly shown in Figure 6(a) that the energy absorbed by the flax specimens slightly exceeds the provided impact energy of the $25 \mathrm{~J}$, therefore a small rebound is evidently present. More specifically, both the glass and the glass/flax hybrid specimens absorbed up to $19 \mathrm{~J}$ when impacted with $25 \mathrm{~J}$ energy. Increasing the impact energy to $50 \mathrm{~J}$, the hybrid specimens exhibited higher energy absorption (34 J) compared to the previous test, due to the perforation that happened. This fact is attributed to the overall performance of the glass/flax specimens, which perforated significantly less during the impact, retaining their resistance, in contrast to the flax specimens.

In accordance to the experimental results, the numerical results derived from the FE model developed to simulate the mass-drop experiments at $25 \mathrm{~J}$ impact energy revealed good similarity. The total displacement of the $6 \times 6 \mathrm{~mm}^{2}$ central area of the specimen is predicted at $10.12 \mathrm{~mm}$. This value is very close to the actual maximum vertical deflection observed on the specimen, which is measured as $11 \mathrm{~mm}$ (Figure 9).

The contact force-displacement curves, as predicted from the FE model for the flax/VE composite plate are compared to the experimental ones and presented in Figure 7. In the initial loading phase of the impact event, there is a similarity in the curve's slope until the maximum force is reached. When the displacement is about $2.7 \mathrm{~mm}$, there start to occur the first delaminations into the composite plate, therefore this small drop in the load is presented. The FE model did not follow this trend precisely, mainly due to the failure data that were imported into the model. At this stage, more accurate experimental measurements need to be conducted in order to extract precise data for the material. Finally, during the unloading phase of Fig. 7, the actual tested specimen recovers with slightly higher displacement than the simulated model. This small difference may be attributed to the assumed friction coefficient between the composite plate and the impactor. 
The contact force-time curves are also presented in Figure 8 in order to demonstrate the capabilities of the model that was developed. From this comparison it is obvious that the developed FE model is very well correlated with the experimental results during the first loading stage of the phenomenon up to $0.84 \mathrm{msec}$. Then, during the initiation of the damage on the components, the model seems to differentiate from the experimental behaviour mainly due to the complex damage mechanisms that take place and cannot be accurately captured. However, the predicted results show a great potential for the flax-vinyl ester specimens.

\section{FAILURE MECHANISMS}

Several failure mechanisms may appear in the composite materials under impact loading, which involve matrix cracking, delamination, fibre breakage and, finally, penetration [15]. It is essential to be able to characterise the type and extension of the damage induced in the impacted specimens. X-ray micro CT is a novel method that shows the propagation of the damage in an orthoslice by orthoslice manner. The basic principle under tomography imaging is related to the X-ray absorption capabilities of the materials. Light absorption in a material is a logarithmic function of its absorption capacity and of the distance that it must travel. In general, for a fixed X-ray photon energy source, elements with a smaller atomic number absorb less radiation than higher atomic number elements [16].

Figure 9 presents the result from the imaging of the flax reinforced composite specimen, which was impacted at $25 \mathrm{~J}$. A conical pattern of damage in the thickness direction is detected, enlarging from the impacted face towards the back face. The specimens' indentation is obvious and the damage area involves a great amount of fibre breakage, which is also visible on the specimen's back surface (Figure 10(b) left). SEM imaging performed on this specimen reveals the fibre breakage around the perforated are of the flax/vinyl ester specimen (Figure 9(d)). Furthermore, comparing the delamination that occurs through the thickness of the flax/vinyl ester specimen, as depicted in Figure 9(a), with the delamination areas as predicted by the FE model (Figure 9(e)) shown in a section of the model on the YZ plane, a good correlation is observed. The model seems to predict a slightly more propagated delamination area compared to the actual delamination size.

On the contrary, the imaging of the hybrid glass/flax specimens reveals that the total deflection is close to the deflection of the glass specimen under the $25 \mathrm{~J}$ impact event, as shown in Figure 11. On the impacted area, the total deflection of the back surface is $5.37 \mathrm{~mm}$ for the hybrid specimen and $3.55 \mathrm{~mm}$ for the glass specimen, whereas the value for the flax specimen is $11.53 \mathrm{~mm}$. The damage modes are similar for these two specimens, exhibiting delamination along the fibre orientations, i.e. on the $\pm 45^{\circ}$, as shown on the photos of the back faces of those specimens in Fig. 10(c) (middle and right). It is worth mentioning that hybrid composites exhibited more delamination than the non-hybrid systems. A zoomed detail of the centre damaged area (circled with red in Fig. 10(a)) of the hybrid specimen is presented in Fig. 10(b), where high delamination cracks are observed through the thickness of the specimen and on both the glass and flax components. A similar zoomed damaged area (as included in the red circle of Fig. 10(c)) for the glass-reinforced specimen is presented in Fig. 10(d). The cracks and voids between the layers are clearly shown through the thickness of the specimen.

The X-ray images show noticeable differences on fracture behaviour with different laminates. Figure 12 presents the propagation of the damage on the XY plane at various distances from the mid-span of the specimen's XY surface for all the specimens when impacted at $25 \mathrm{~J}$. Areas of delaminations and large cracks have been initiated with a direction vertical to the impact velocity that seem to propagate. These cracks are shown with circles in red in Fig. 12 and it is obvious that the delamination cracks increase in length as approaching the maximum deflection of the plate. Matrix cracks are also observed, especially for the hybrid specimens (yellow circles in row (iv) of Fig. 12), whereas delaminations are not so dominant in 
these specimens under the $25 \mathrm{~J}$ impact event. This is a good indication of the cohesive behaviour of the hybrid material. On the contrary, the flax only specimen appear to have perforated under the same impact energy and bid debonding areas between the layers are observed, which ultimately reduce the overall performance of the component.

The damaged area at the $50 \mathrm{~J}$ of impact energy is more obvious on the specimens' surfaces, as shown in Figure 13. From this figure, it is apparent that the flax/VE specimens have undergone the most severe damage and penetration is present. The glass/VE and the hybrid specimens (middle and right photos of Fig. 12) show similar damage characteristics. A typical middle slice for each specimen, as extracted from the $\mathrm{X}$-ray imaging process, is shown in Figure 14. Again, major delamination are dominating the (b) and (c) specimens of Fig. 13. Additionally, the hybrid specimens (Fig. 14(c)) exhibit large matrix cracks on all the flax layers.

SEM imaging results have been extracted for all the specimens when impacted at $50 \mathrm{~J}$. The fibre breakage is obvious and clear to identify for the flax/vinyl ester specimens, as shown in Figure 15 at the exact point of perforation for $\times 57$ and $\times 150$ magnification.

The glass/vinyl ester specimen exhibited less damage at the same energy level, which is apparent in the

SEM images of Figure 16. The fibre pull out can be observed on the surface of the specimen (Fig. 16(a)), whereas various cracks have initiated on the specimen's surface with fibre pull out as well (Fig. 16(b)). The hybrid specimen exhibits areas with delaminations through the thickness of the specimen (as shown in Fig. 14(c)). Closer images of these delamination areas give more insight to the damage mechanisms, where the debonding of the layers is dominant (Fig. 16(c,d)).

\section{CONCLUSIONS}

In this study, low velocity induced damage of flax, glass and glass flax hybridised composite laminates at two incident energy levels were investigated, both experimentally and numerically. Micro-CT was used to evaluate the damage mechanisms. The results exhibited a significant improvement in the impact damage characteristics such as impact load capability and absorbed energy of flax natural fibre composite with the introduction of glass fibre as hybrid reinforcement.

The experimental results at two different impact energies (25 J and $50 \mathrm{~J}$ ) confirmed the fact that the flax specimens can absorb more energy during the impact event, but they tend to show greater damage extension at lower energy levels compared to the glass/flax specimens. In fact, the hybrid specimens exhibited similar behaviour as the glass fibre reinforced plates, but with the advantage of the lower density, renewable flax fibres. The finite element model that was developed was able to simulate the impact event in close agreement with the experimental results and, therefore, can become a valid and robust prediction of the materials behaviour subject to low-velocity impact loadings. The X-ray micro CT technique that was used to further investigate the impact damage, revealed a big amount of matrix cracks and fibre/matrix interface debonding occurring for both impact energies in the glass/flax specimens. With more detailed implementation of this technique, smaller scale damage characteristics will be able to be assessed and further understand the damage propagation processes. Overall, the hybridisation of the flax reinforced natural fibre composite reveals a much higher impact performance, exhibiting greater perforation and penetration resistance with the benefits of having lower environmental impact than glass fibre laminates without hybridisation. With adequate design, flax/glass hybrid system can provide a balance property between performance and environmental benefits 


\section{ACKNOWLEDGEMENTS}

This research did not receive any specific grant from funding agencies in the public, commercial, or notfor-profit sector.

\section{DATA AVAILABITLITY}

The raw/processed data required to reproduce these findings cannot be shared at this time as the data also forms part of an ongoing study. 


\section{REFERENCES}

1. Shahzad A., 2012 'Hemp fibre and its compoistes - a review', Journal of Composite Materials, Vol. 46, pp. 973-986.

2. Dhakal H.N., Zhang Z.Y., Richardson M.O.W., et al., 2007 'The low velocity impact response of non-woven hemp fibre reinforced unsaturated polyester composites', Composite Structures, Vol. 81, pp. 559-567.

3. Karus M., Kaup M., 2002 'Natural fibres in the European automotive industry', Journal of Industrial Hemp, Vol. 7, pp. 117-129

4. Rana A.K., Mandal A., Bandyopadhya S., 2003 'Short jute fibre reinforced polypropylene composites: effects of compatibiliser, impact modification and fibre loading', Composites Science and Technology, Vol. 63, pp. 801-806

5. Bledski A.K., Gassan J, Zhang W., 1999 'Impact properties of natural fibre reinforced epoxy foams', Journal of Cellular Plastics, Vol. 35, pp. 550-562

6. Wang S., Chung D.D.L., Chung J.H., 2005 'Impact damage of carbon fibre polymer-matric composites, studied by electrical resistance measurement', Composites: Part A, Vol. 36, pp. 17071715

7. Mitrevski T., Marshall I.H., Thomson R., 2006 'The influence of impactor shape on the damage to composite laminates', Composite Structures, Vol. 76, pp. 116-122

8. Wisheart M., Richardson M.O.W., 1999 'Low velocity response of a complex geometry pultruded glass/polyester composite', Journal of Material Science, Vol. 34, pp. 1107-1116

9. Shen W.Q., 1997 'Dynamic response of rectangular plates under drop mass impact', International Journal of Impact Engineering, Vol. 19, pp. 207-229

10. Mei H., Yu C., Xu Y., Han D., Cheng L., 2017 'Effect of impact energy on damage resistance and mechanical property of $\mathrm{C} / \mathrm{SiC}$ composites under low velocity impact', Materials Science \& Engineering A, Vol. 687, pp. 141-147

11. Elias A., Laurin F., Kaminski M., Gornet L., 2017 'Experimental and numerical investigations of low energy/velocity impact damage generated in 3D woven composite with polymer matrix', Composite Structures, Vol. 159, pp. 228-239

12. Theodosiou T.C., Rekatsinas C.S., Nastos C.V., Saravanos D.A., 2016 'Identification of impact events on composite plates using wave characteristics and impact similarity laws', $8^{\text {th }}$ European Workshop on Structural Health Monitoring, Spain

13. Siorikis, D.K., Rekatsinas, C.S., Christoforou, A.P., Saravanos, D.A., 2017, 'Experimental and numerical investigation of contact laws for the rapid simulation of low-energy impacts on laminated composite plates', Composite Structures, Vol. 168, pp. 646-656

14. Dhakal H.N, Zhang Z.Y., Richardson M.O.W., Errajhi O.A.Z., 2007 'The low velocity impact response of non-woven hemp fibre reinforced unsaturated polyester composites', Composite Structures, Vol. 81, pp. 559-567

15. Dhakal H.N., Zhang Z.Y., Bennett N., Reis P.N.B., 2012 'Low-velocity impact response of nonwoven hemp fibre reinforced unsaturated polyester composites: Influence of impactor geometry and impact velocity', Composite Structures, Vol. 94, pp. 2756-2763

16. Touchard F., Boustie M., Chocinski-Arnault L., et al, 2016 'Mechanical and laser impact effects on woven composites with hemp or glass fibres', International Journal of Structural Integrity, Vol. 8, No. 3, pp. 286-307

17. Cantwell WJ, Morton J., 1991 'The impact resistance of composite materials: a review', Composites, 22(5):347-62.

18. Dhakal, H. N., Zhang, Z. Y., Guthrie, R., \& Bennett, N., 2013 'Development of flax/carbon fibre hybrid composites for enhanced properties', Journal of Carbohydrate Polymers, 96:1-8.

19. Almansour, F. A., Dhakal, H. N., Zhang, Z.Y., 2018 'Investigation into mode II interlaminar fracture toughness characteristics of flax/basalt reinforced vinyl ester hybrid composites', Composites Science and Technology, 154:117-127. 
20. Kumar C.S., Arumugam V., Dhakal, H.N., John R., 2015 'Effect of temperature and hybridization on the low velocity impact behaviour of hemp-basalt/epoxy composites', Composite Structures, 125:407-416.

21. Garcea S.C., Wang Y., Withers P.J., 2017 'X-ray computer tomography of polymer composites', Composites Science and Technology, In press

22. Little J.E., Yuan X., Jones M.I., 2012 'Characterisation of voids in fibre reinforced composite materials', NDT \& E International, Vol. 46, No. 0, pp. 122-127

23. Leonard F., Stein J., Soutis C, Withers P.J., 2017 'The quantification of impact damage distribution in composite laminates by analysis of X-ray computed tomograms', Composites Science and Technology, Vol. 152, pp. 139-148

24. Li Y., Sun B., Gu B., 2017 'Impact shear damage characterizations of 3D braided composite with $\mathrm{X}$-ray micro-computed tomography and numerical methodologies', Composite Structures, Vol. 176, pp. 43-54

25. Determination of puncture impact behaviour of rigid plastics. British Standard, Part 2: Instrumented Puncture Testing. BS EN ISO 6603-2:2000

26. Hashin Z., 1980, 'Failure criteria for unidirectional fibre composites', ASME Journal of Applied Mechanics, Vol. 47 (2), pp 329-334.

27. Koh, R., Madsen, B., 2018, 'Strength failure criteria analysis for a flax fibre reinforced composite', Mechanics of Materials, Vol. 124, pp. 26-32

28. Chang F.K., Chang, K.Y., 1987, 'A progressive damage model for laminated composites containing stress concentration', Journal of Composite Materials, Vol. 19(9), pp. 834-855

\section{FIGURE CAPTION}

Figure 1. (a) Test specimens for the drop-weight impact experiment; (a) Flax fibre reinforced vinyl ester composite plate, (b) glass fibre reinforced vinyl ester composite plate and (c) flax/glass hybrid fibre reinforced vinyl ester composite plate. (d) Through the thickness layers configuration for the flax and glass composite specimens; (e) Through the thickness layup configuration for the hybrid specimens

Figure 2. The instrumented drop-tower arrangement on the IFW 413 impact machine. (a) Enlarged view of the hemispherical tup; (b) enlarged view of clamping mechanism.

Figure 3. The meshed FE model of the $1 / 4^{\text {th }}$ of the flax fibre reinforced composite plate with the impactor.

Figure 4. Load-time curves for Glass, Flax and Glass/Flax reinforced composites under (a) $25 \mathrm{~J}$ and (b) 50 $\mathrm{J}$ impact energy.

Figure 5. Load-displacement curves for Flax and Carbon/Flax reinforced composites under (a) $25 \mathrm{~J}$ and (b) $35 \mathrm{~J}$ impact energy.

Figure 6. Absorbed energy vs. time curves for flax, glass and hybrid glass/flax reinforced composites under (a) $25 \mathrm{~J}$ and (b) $50 \mathrm{~J}$ impact energy.

Figure 7. Experimental and numerical impact force-displacement histories at $25 \mathrm{~J}$ of impact energy.

Figure 8. Experimental and numerical impact force-time histories at $25 \mathrm{~J}$ of impact energy. 
Figure 9. micro-CT images of impacted flax specimen tested at $25 \mathrm{~J}$. (a) XY plane, (b) top surface, (c) bottom surface, (d) SEM image of the damaged area at x58 magnification. (e) Prediction of delamination areas from the FE model of the flax/vinylester specimen.

Figure 10. Impacted images of the flax fibre reinforced, glass fibre reinforced and flax/glass fibre hybrid reinforced composite specimen (from left to right) after the impact event at $25 \mathrm{~J}$. (a) Front face; (b) back face.

Figure 11. Cross-sectional X-ray image of the XY plane of the (a) hybrid glass/flax specimen and (b) the glass fibre reinforced composite specimen.

Figure 12. (i) Damage propagation along the length for 5 ( $a, b, c, d \&$ e) discrete points of interest on the specimen's damaged area; (ii) for flax/VE, (iii) glass/VE and (iv) hybrid glass-flax/VE composite specimens.

Figure 13. Photos of the flax fibre reinforced, glass fibre reinforced and flax/glass fibre hybrid reinforced composite specimen (from left to right) after the impact event at $50 \mathrm{~J}$. (a) Front face; (b) back face.

Figure 14. Cross-sectional X-ray image of the XY plane of the (a) flax fibre, (b) glass fibre and (c) hybrid glass/flax reinforced composite specimen.

Figure 15. SEM images for the flax/vinyl ester specimen impacted at $50 \mathrm{~J}$. Images are zoomed at the perforated area. (a) x57 magnification; (b) x150 magnification

Figure 16. SEM images of the damaged specimens when impacted at $50 \mathrm{~J}$ : (a) fibre pull out at the glass/vinyl ester specimen; (b) crack on surface of the glass/vinyl ester specimen; (c)-(d) delamination cracks through the thickness of the hybrid specimens.

\section{TABLE CAPTION}

Table 1. Mechanical and physical properties of flax fibre reinforced vinyl ester composite laminate [27]

\begin{tabular}{llll}
\hline Mechanical properties & & Strength $(\mathbf{M P a})$ \\
\hline Longitudinal modulus, $\mathrm{E}_{1}(\mathrm{GPa})$ & 134 & Longitudinal tensile strength, $\mathrm{X}^{\mathrm{T}}$ & 240 \\
Transverse modulus, $\mathrm{E}_{2}(\mathrm{GPa})$ & 27.2 & Longitudinal compressive strength, $\mathrm{X}^{\mathrm{C}}$ & 112 \\
In-plane shear modulus, $\mathrm{G}_{12}(\mathrm{GPa})$ & 4.4 & Transverse tensile strength, Y & 20 \\
Poisson's ratio, v12 & 0.1 & Transverse compressive strength, Y & 97 \\
& & Longitudinal shear strength, $\mathrm{S}^{\mathrm{L}}$ & 37 \\
Density $\left(\mathrm{kg} / \mathrm{m}^{3}\right)$ & 1260 & Transverse shear strength, $\mathrm{S}^{\mathrm{T}}$ & 87 \\
\hline
\end{tabular}




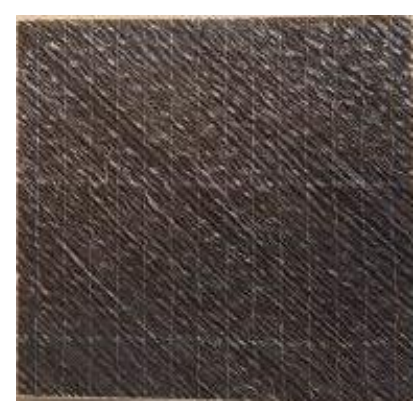

(a)

Figure 1. (a) Test specimens for the drop-weigh (c) flax/glass hybrid fibre reinforced vinyl ester composite plate. (d) Through the thickness layers configuration for the flax and glass composite specimens; (e) Through the thickness layup configuration for the hybrid specimens

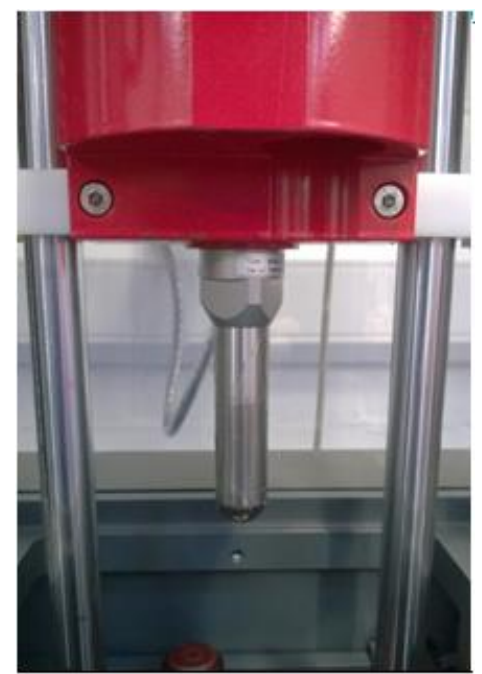

(a)

Figure 2. The instrumented drop-tower arrangement on the IFW 413 impact machine. (a) Enlarged view of the hemispherical tup; (b) enlarged view of clamping mechanism.

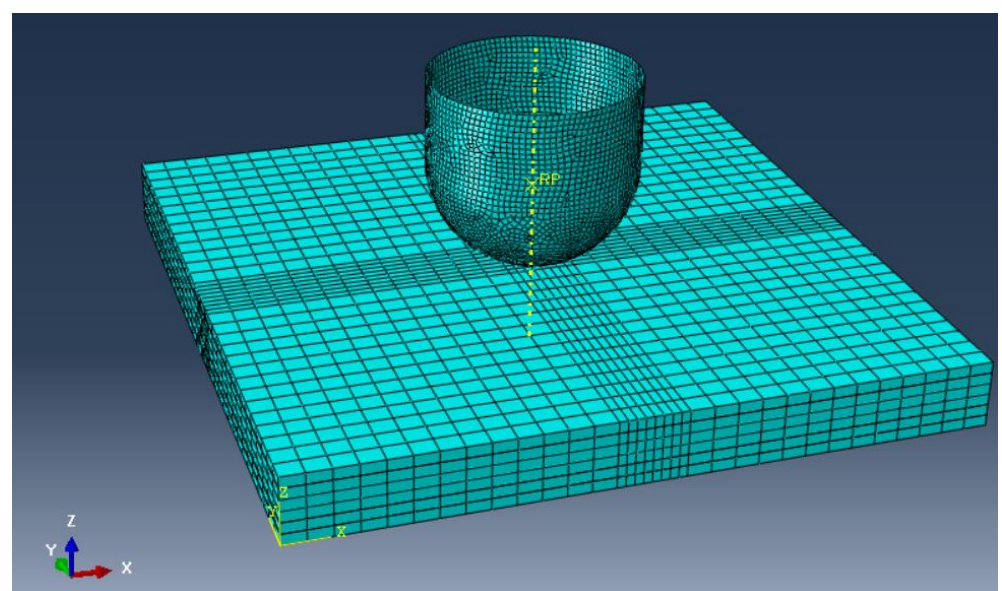

Figure 3. The meshed FE model of the $1 / 4^{\text {th }}$ of the flax fibre reinforced composite plate with the impactor.

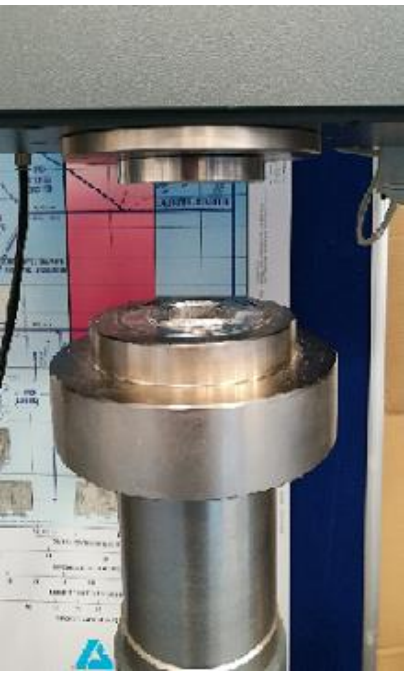

(b)

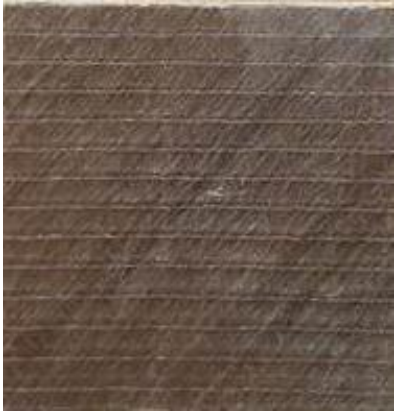

(c) 


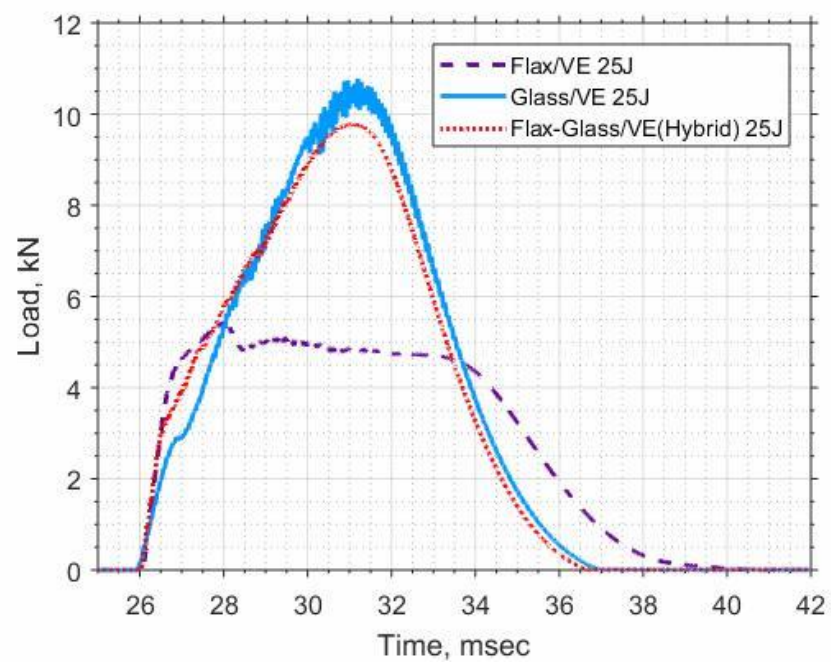

(a)

Figure 4. Load-time curves for Glass, Flax and Glass/Flax reinforced composites under (a) $25 \mathrm{~J}$ and (b) $50 \mathrm{~J}$ impact energy.

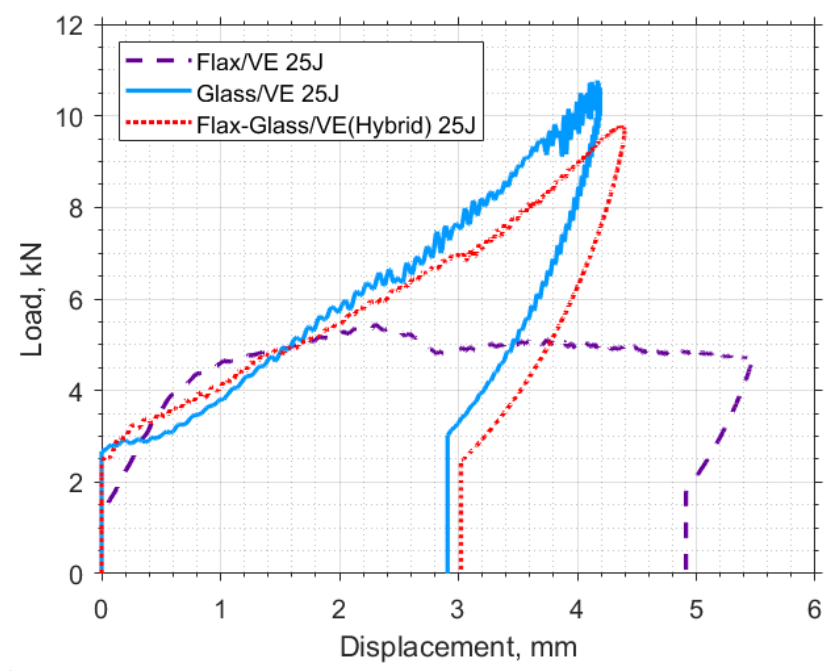

(a)

Figure 5. Load-displacement curves for Flax and Carbon/Flax reinforced

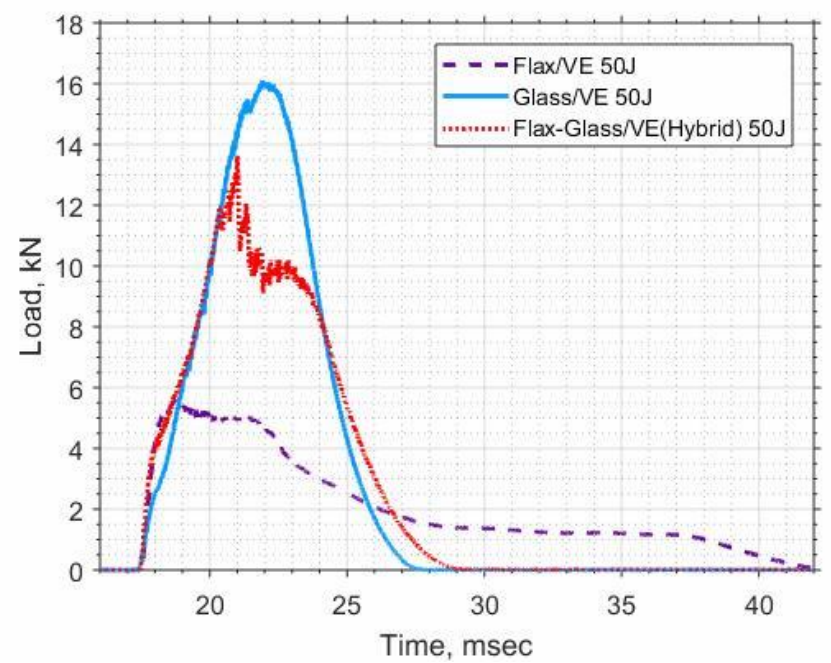

(b)

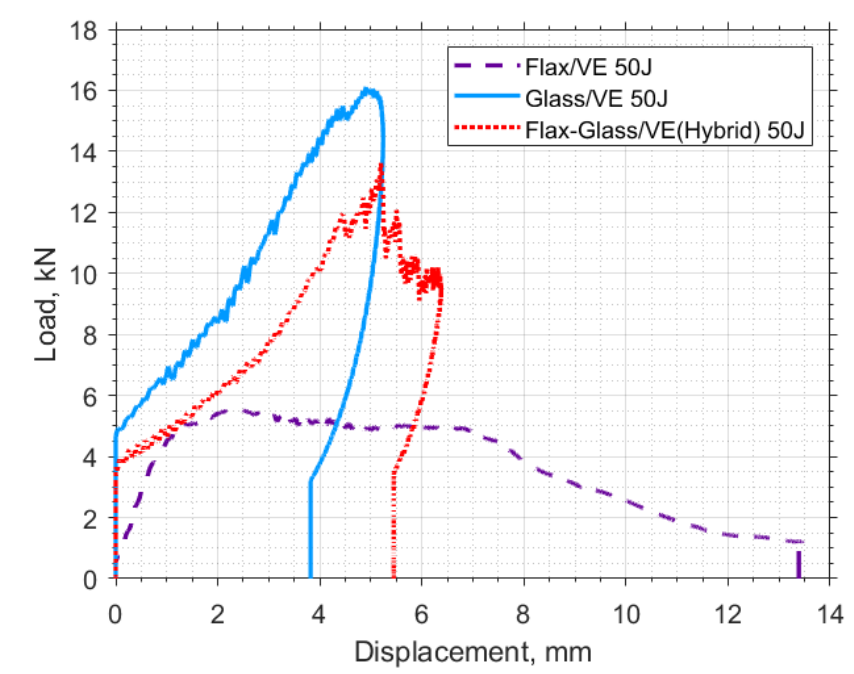

(b)

(a) $25 \mathrm{~J}$ and (b) $35 \mathrm{~J}$ impact energy. 


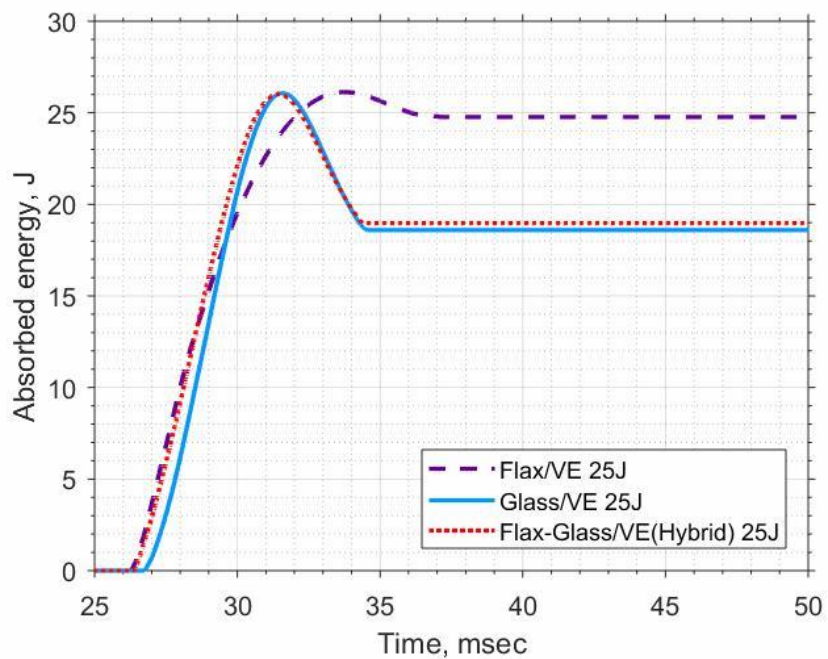

(a)

Figure 6. Absorbed energy vs. time curves for flax, glass and hybrid glass/flax reinforced composites under (a) $25 \mathrm{~J}$ and (b) $50 \mathrm{~J}$ impact energy.

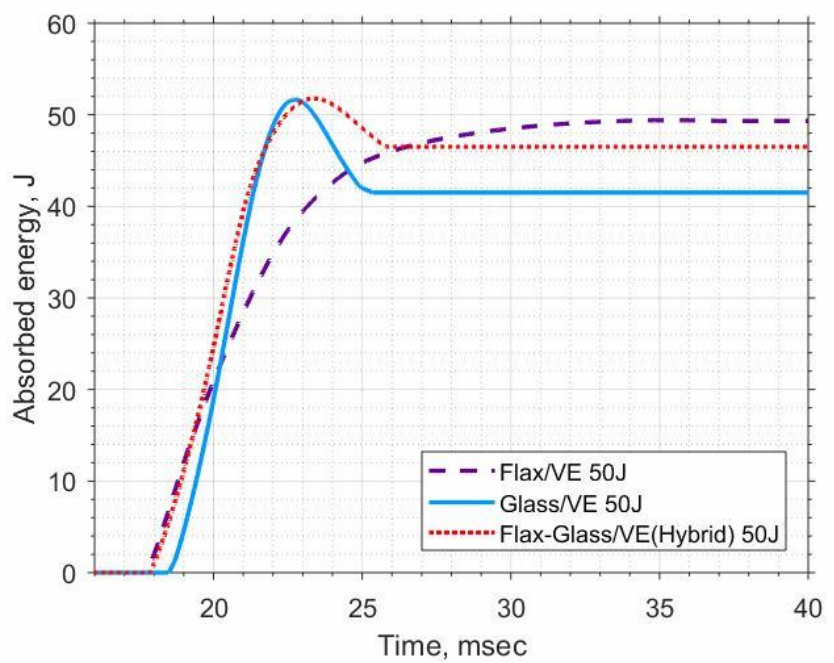

(b)

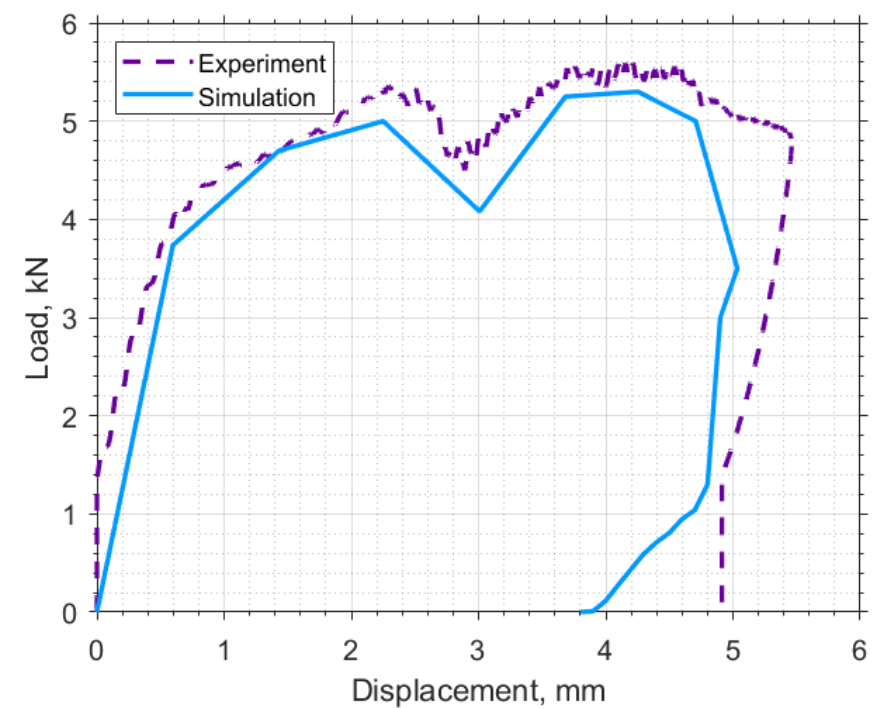

Figure 7. Experimental and numerical impact force-displacement histories at $25 \mathrm{~J}$ of impact energy. 


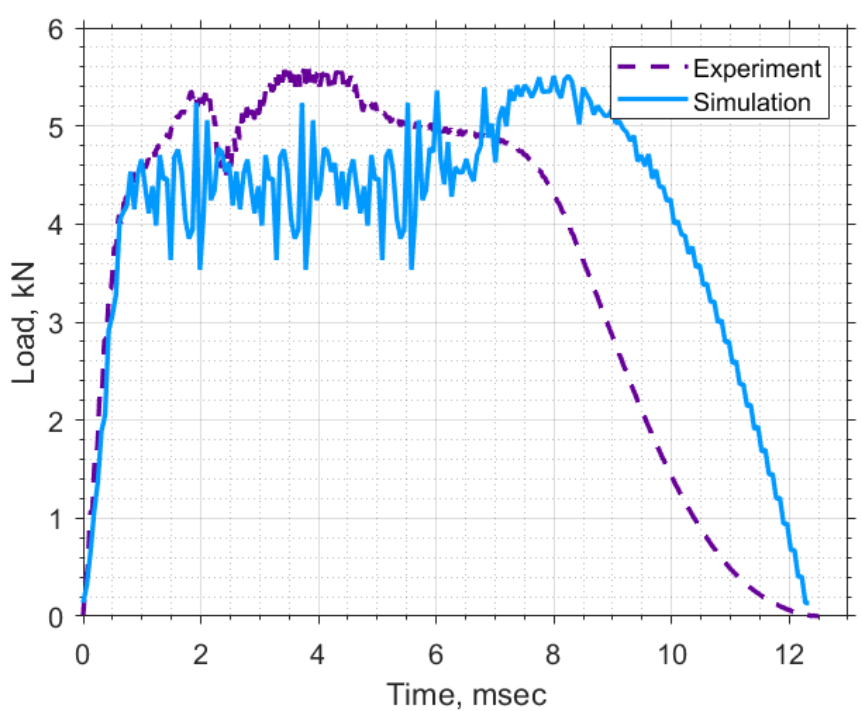

Figure 8. Experimental and numerical impact force-time histories at $25 \mathrm{~J}$ of impact energy. 

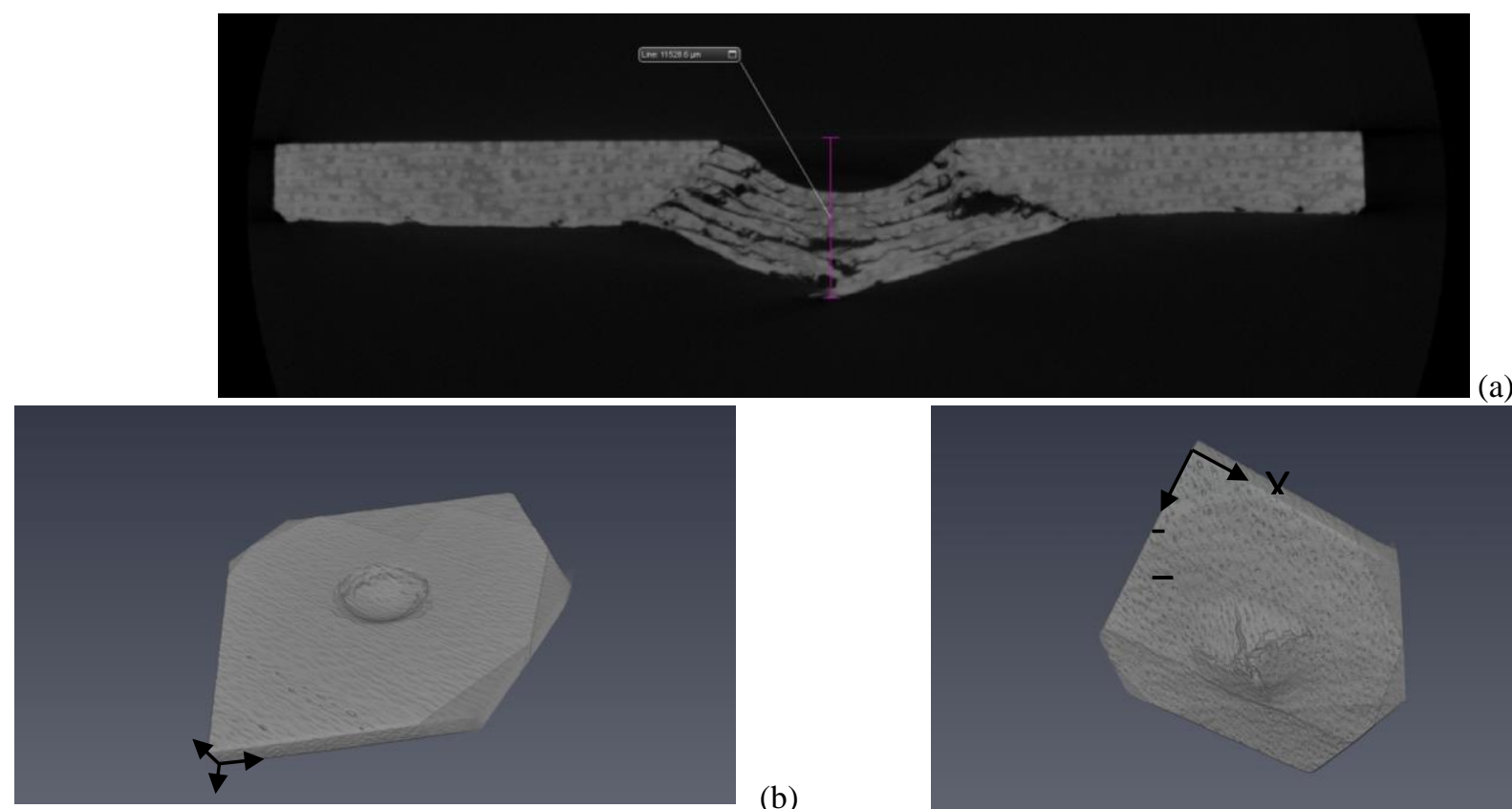

(b)
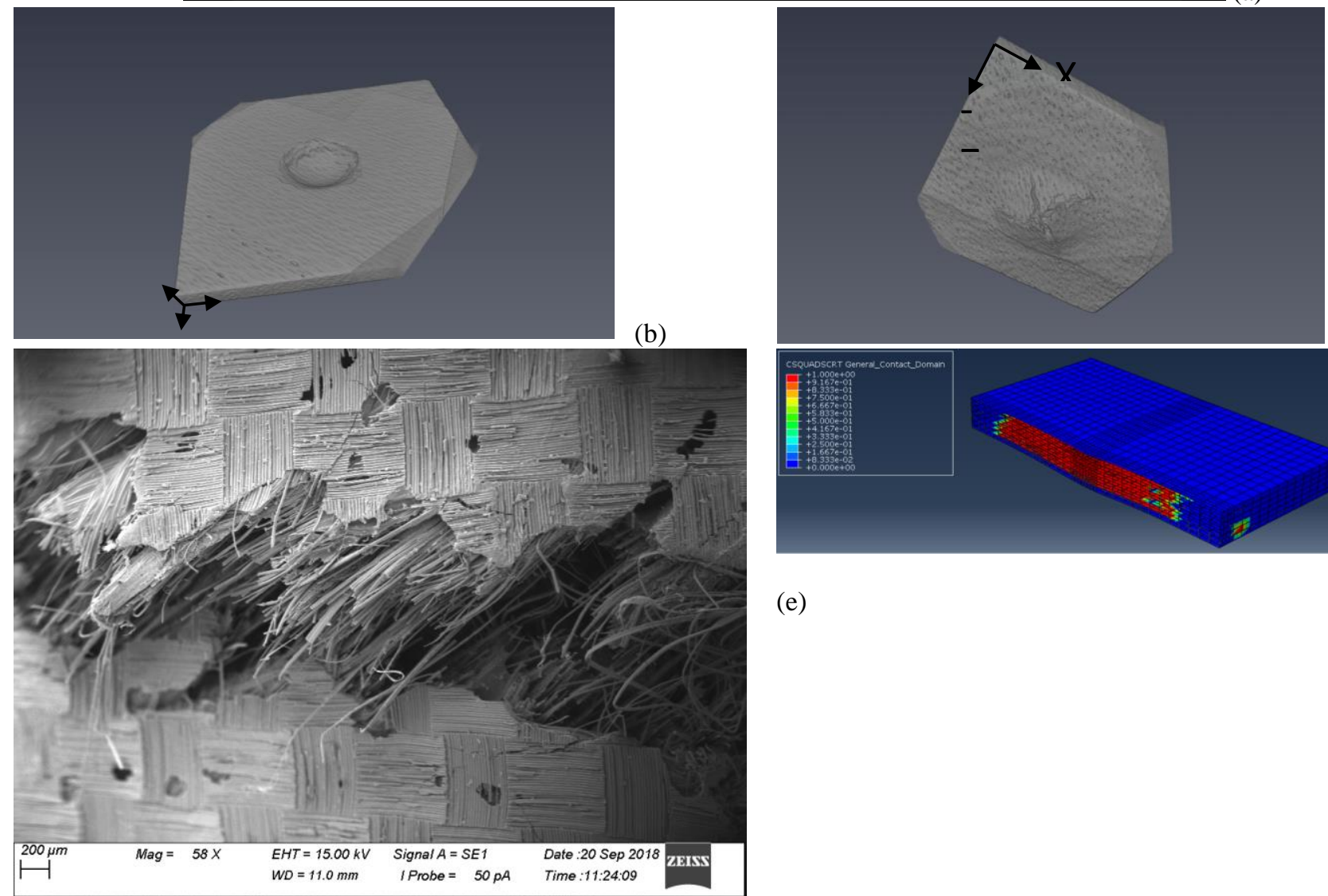

(c)

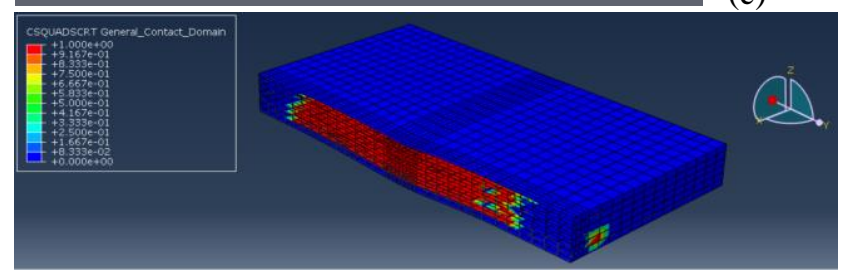

(e)

(d)

Figure 9. micro-CT images of impacted flax specimen tested at 25 J. (a) XY plane, (b) top surface, (c) bottom surface, (d) SEM image of the damaged area at x58 magnification. (e) Prediction of delamination areas from the FE model of the flax/vinylester specimen. 

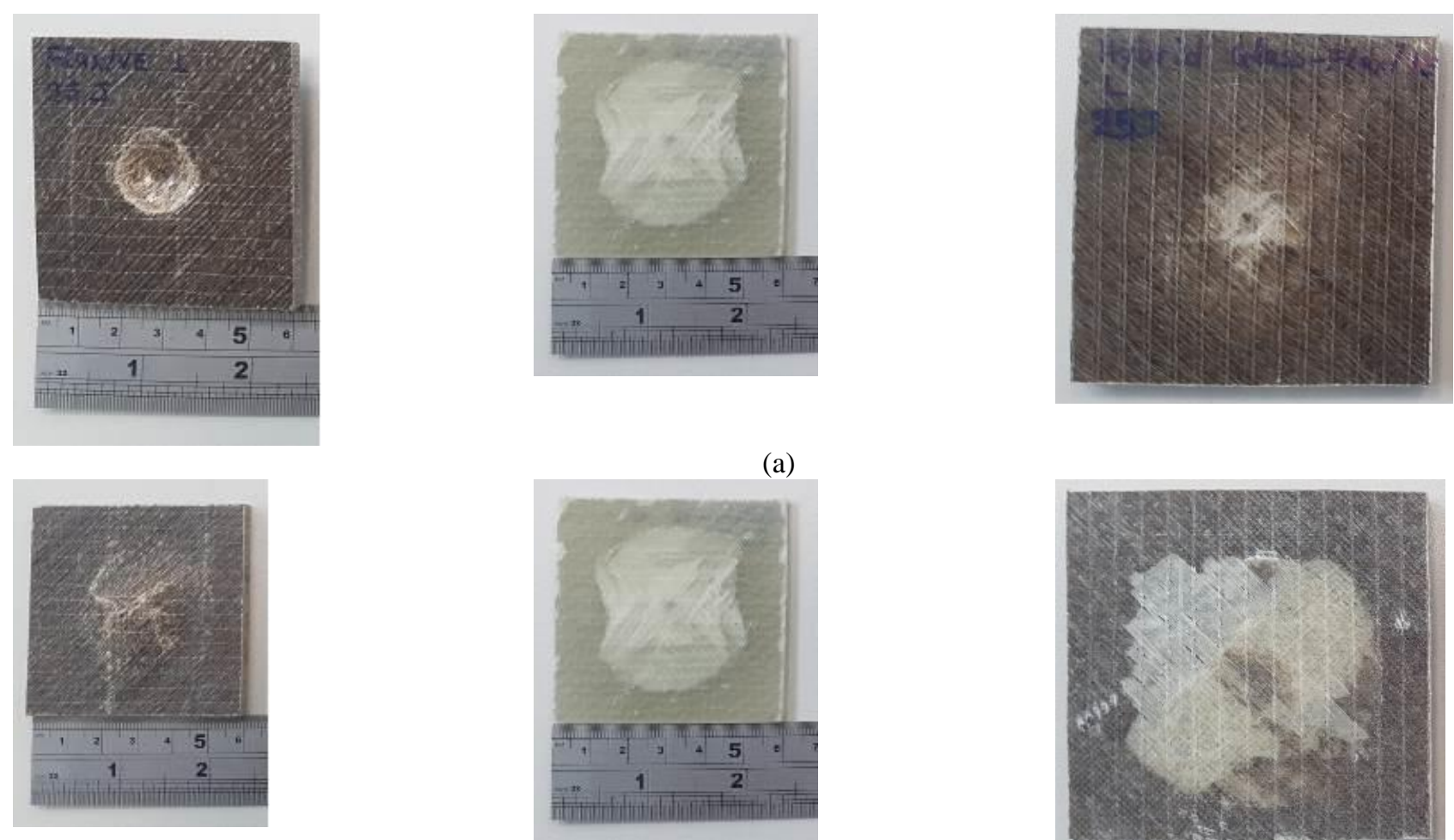

(a)
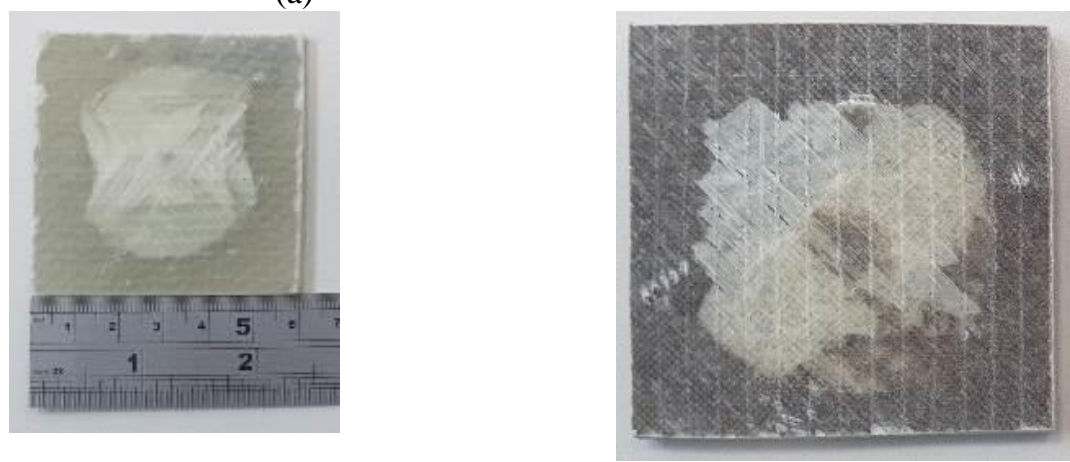

(b)

Figure 10. Impacted images of the flax fibre reinforced, glass fibre reinforced and flax/glass fibre hybrid reinforced composite specimen (from left to right) after the impact event at $25 \mathrm{~J}$. (a) Front face; (b) back face. 

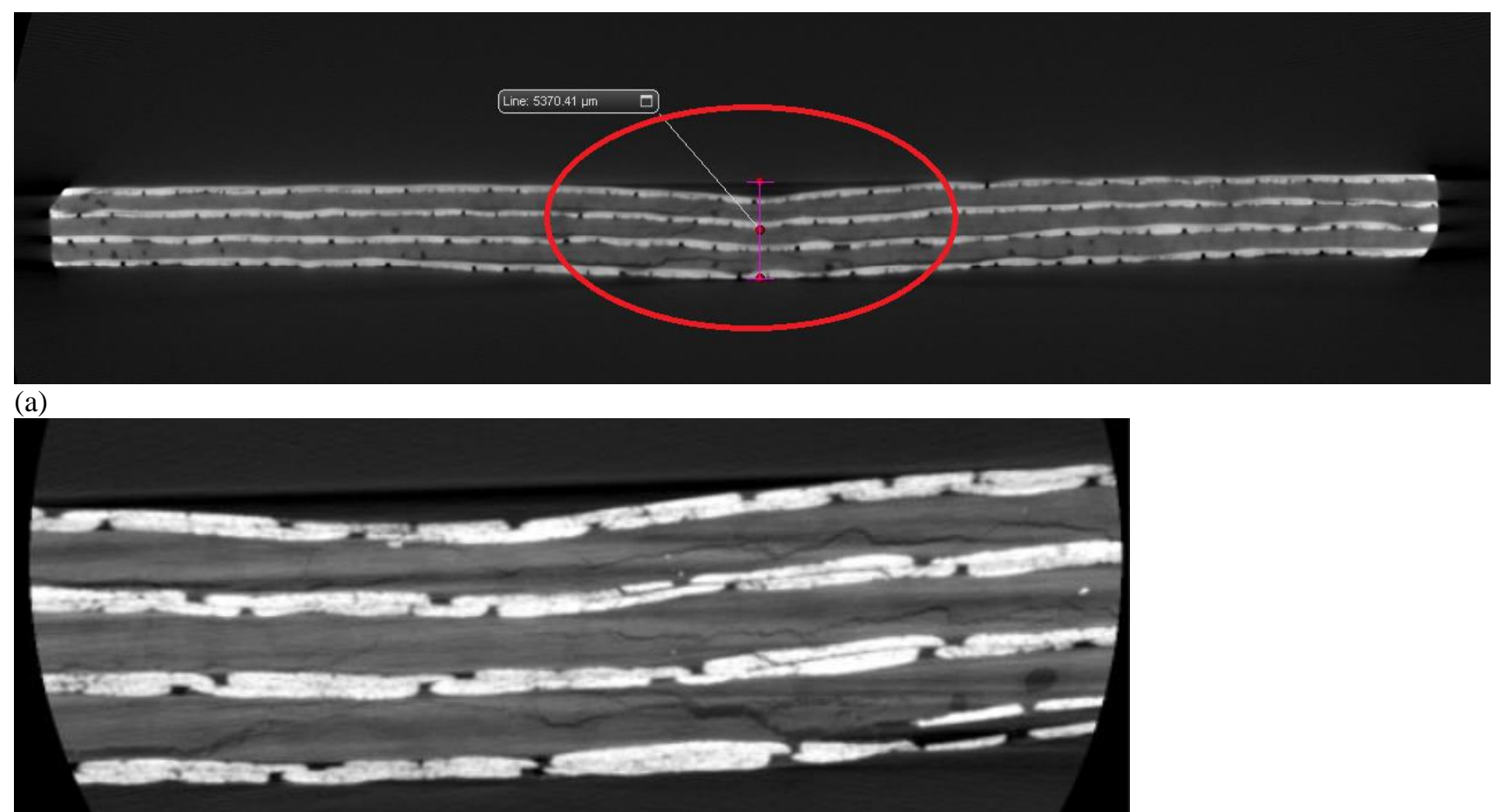

(b)

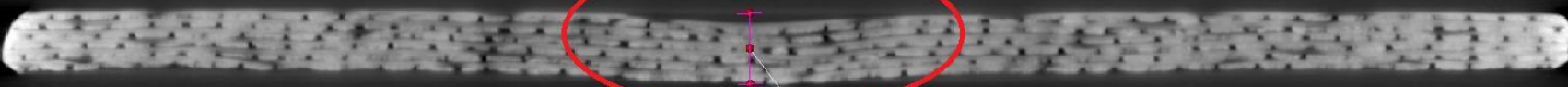

$$
\text { Line } 3554.32 \mu \mathrm{m} \quad \square
$$

(c)

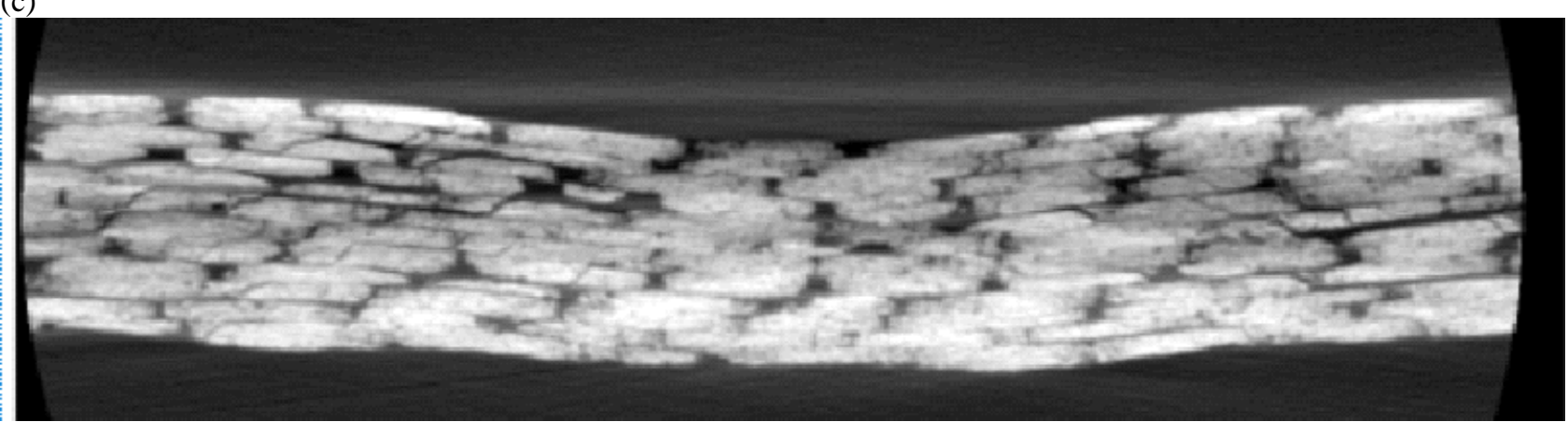

(d)

Figure 11. Cross-sectional X-ray image of the XY plane of the (a) hybrid glass/flax specimen and (b) the glass fibre reinforced composite specimen. 


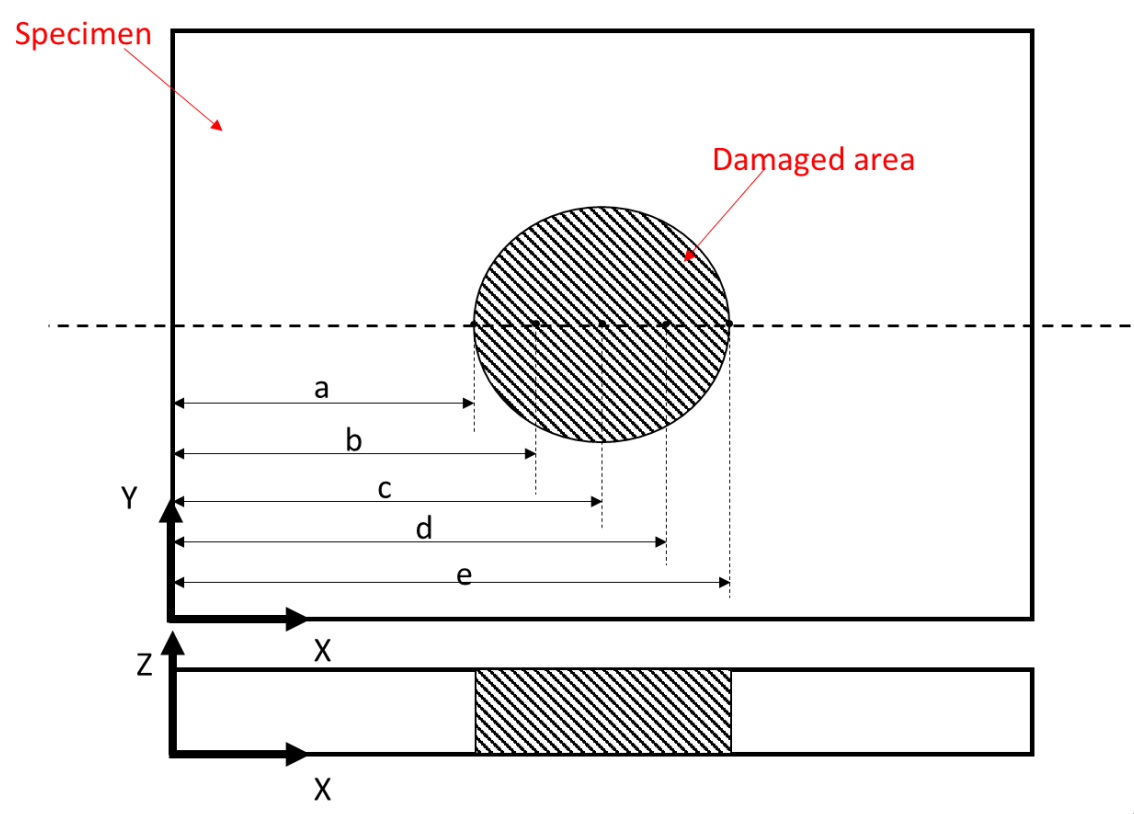

(i)

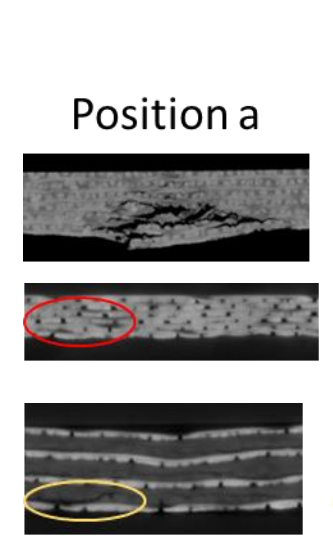

Positions of interest along $x$-axis ( $a, b, c, d \& e)$
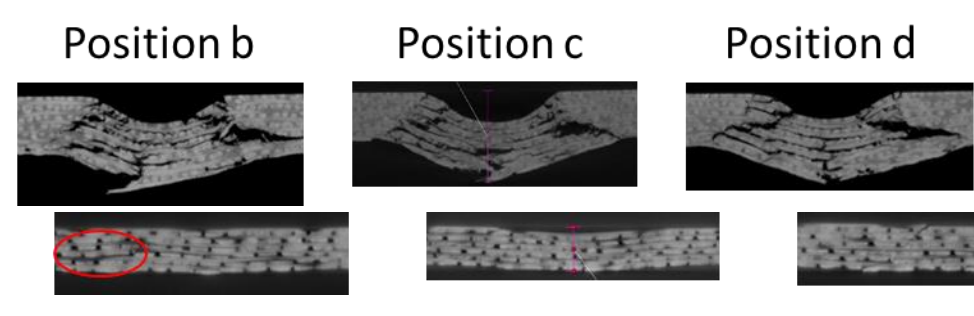

Position e
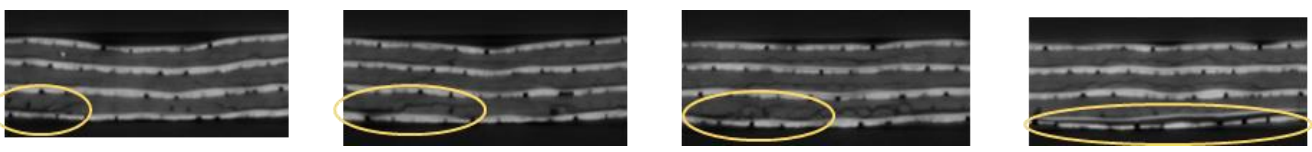

(iv)

Figure 12. (i) Damage propagation along the length for 5 (a, b, c, d \& e) discrete points of interest on the specimen's damaged area; (ii) for flax/VE, (iii) glass/VE and (iv) hybrid glass-flax/VE composite specimens. 

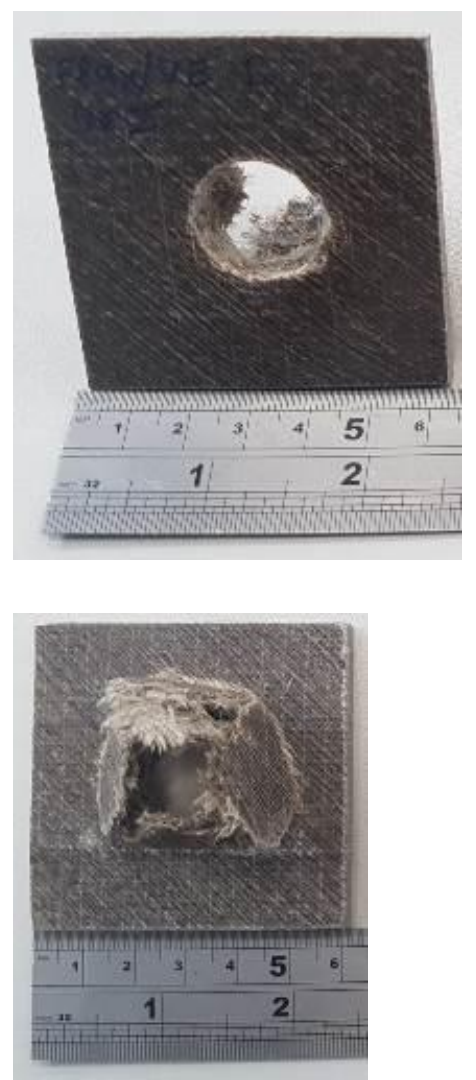
(from left to right) after the impact event at $50 \mathrm{~J}$. (a) Front face; (b) back face.

Figure 13. Photos of the flax fibre reinforced, glass fibre reinforced and flax/glass fibre hybrid reinforced composite specimen

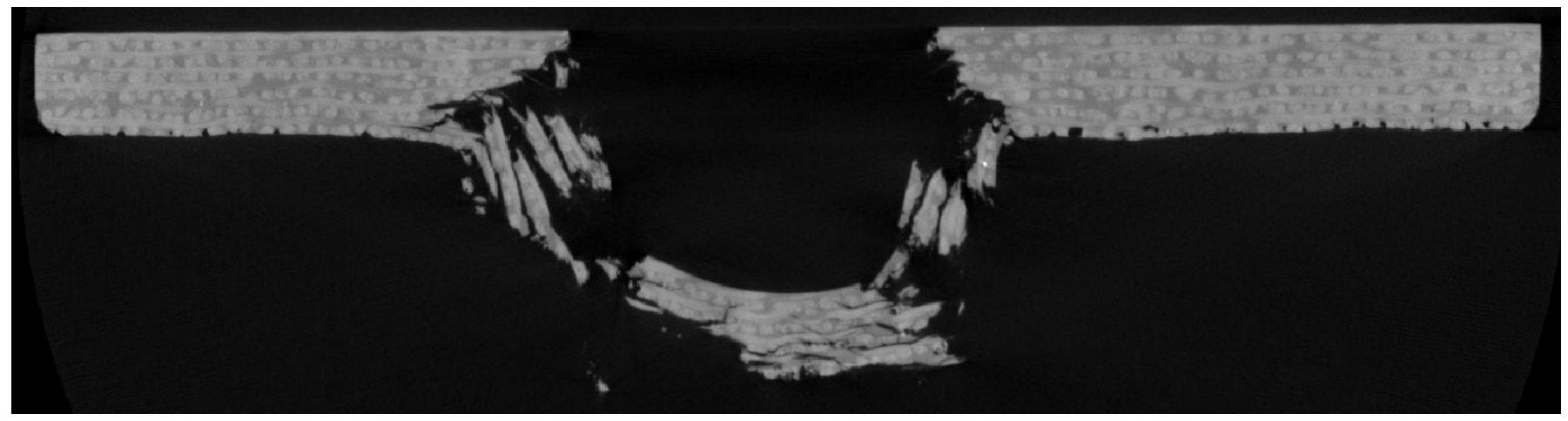

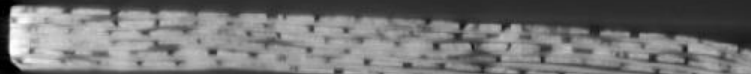
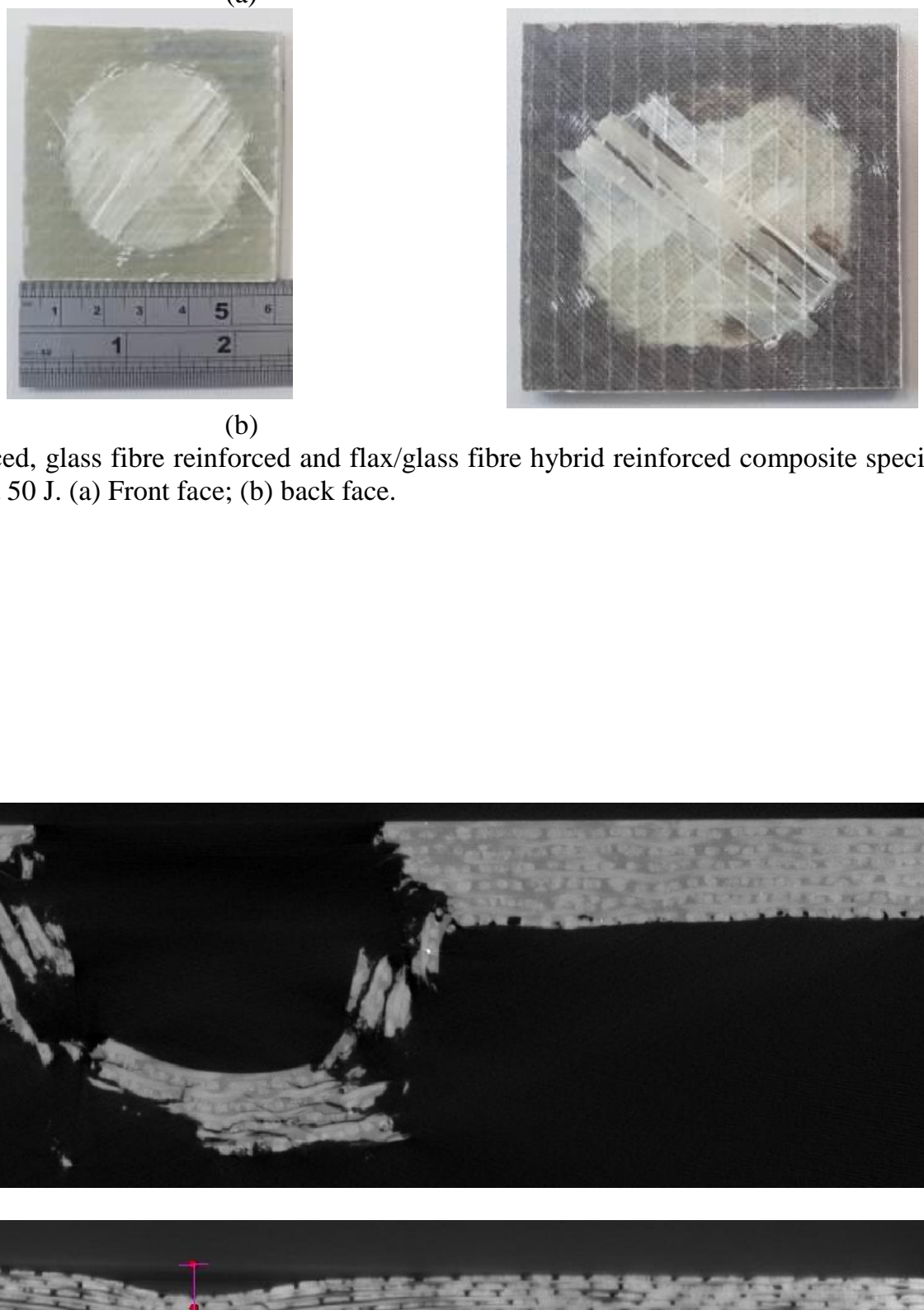

men 


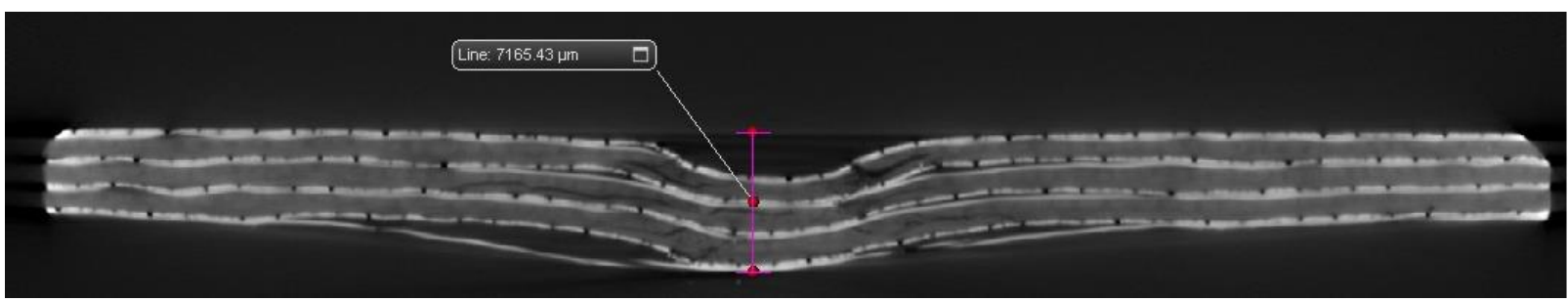

Figure 14. Cross-sectional X-ray image of the XY plane of the (a) flax fibre, (b) glass fibre and (c) hybrid glass/flax reinforced composite specimen.

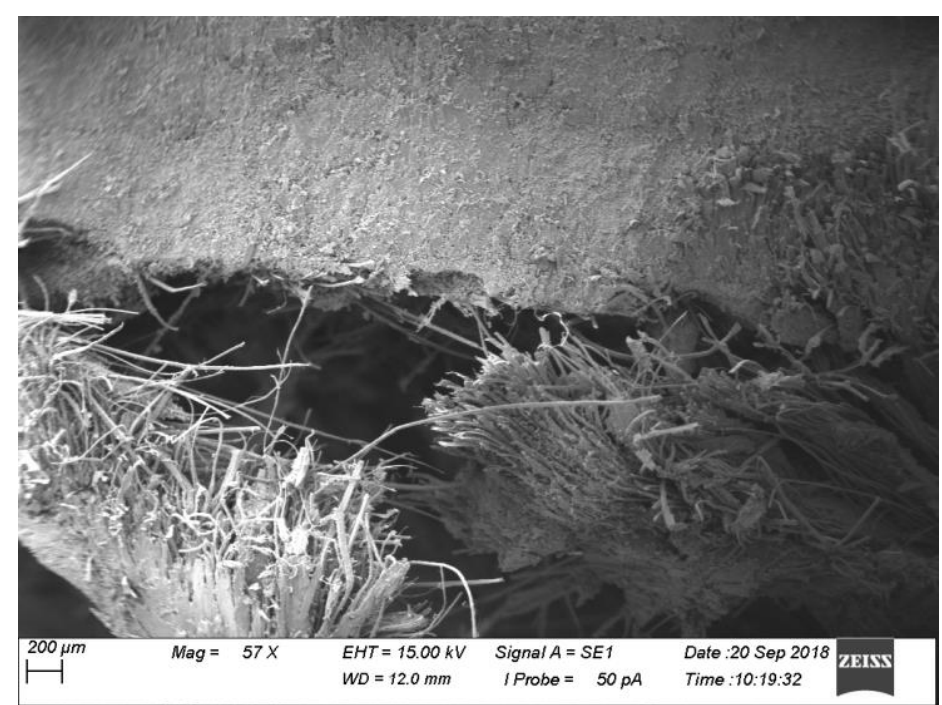

(a)

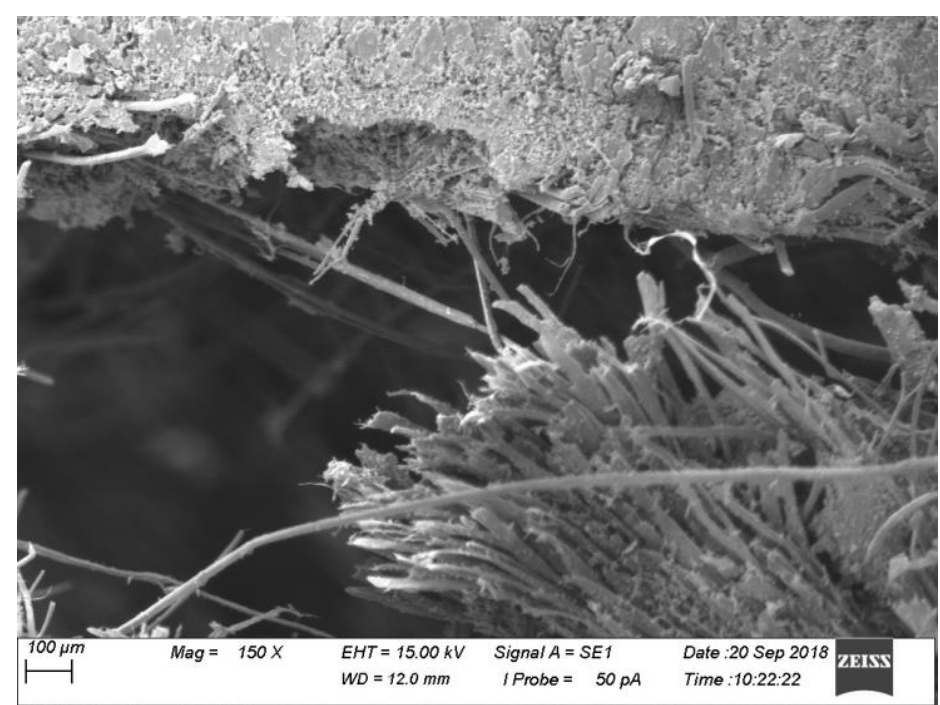

(b)

Figure 15. SEM images for the flax/vinyl ester specimen impacted at $50 \mathrm{~J}$. Images are zoomed at the perforated area. (a) x57 magnification; (b) x150 magnification 


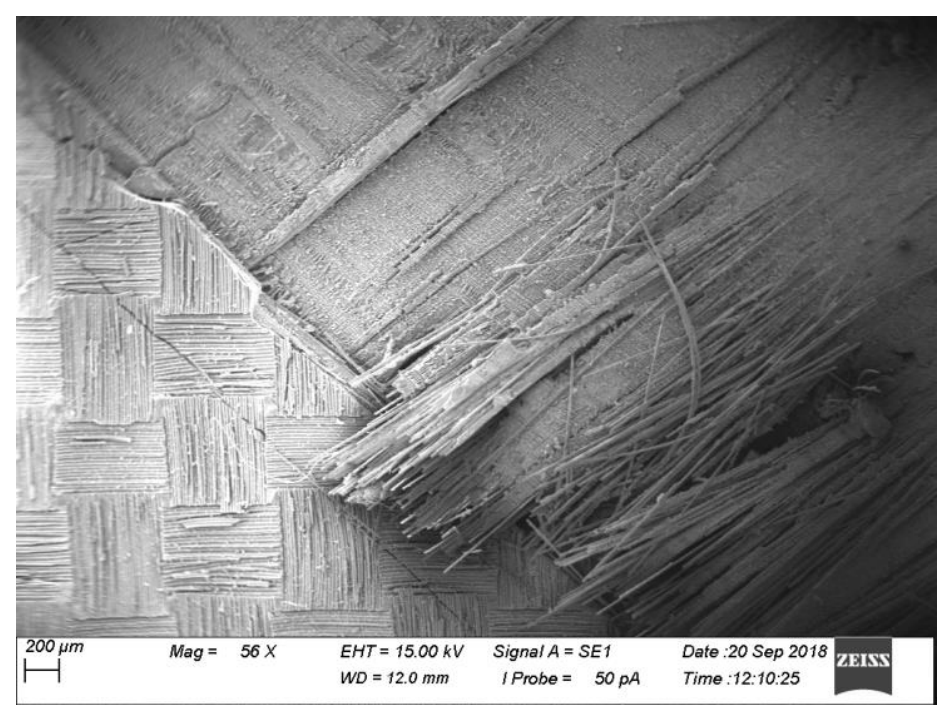

(a)

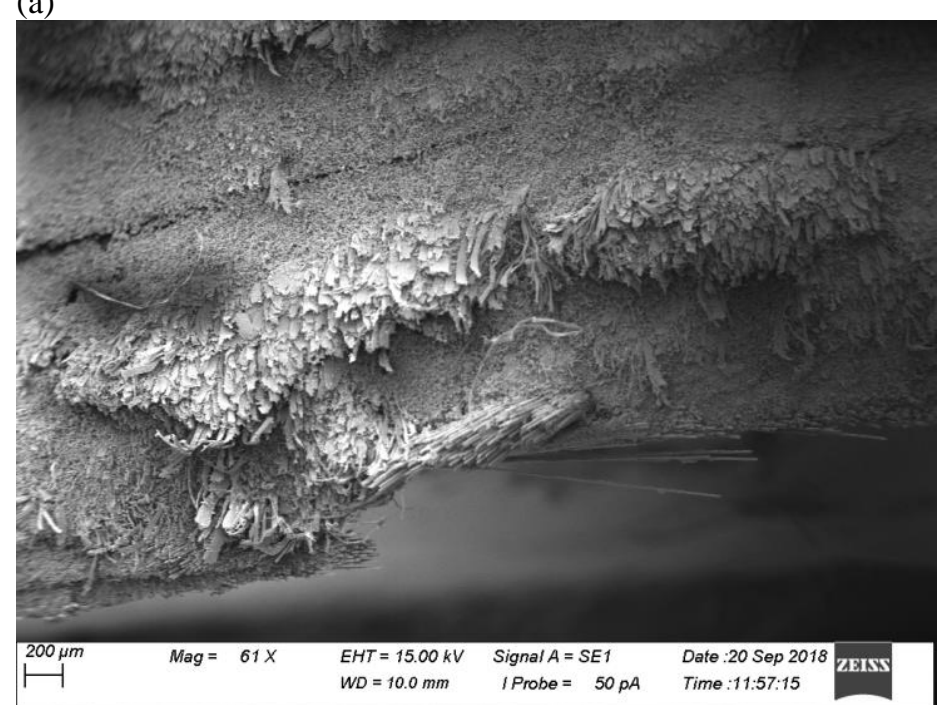

(c)

Figure 16. SEM images of the damaged specimens when impacted at $50 \mathrm{~J}$ : (a) fibre pull out at the glass/vinyl ester specimen; (b) crack on surface of the glass/vinyl ester specimen; (c)-(d) delamination cracks through the thickness of the hybrid specimens.

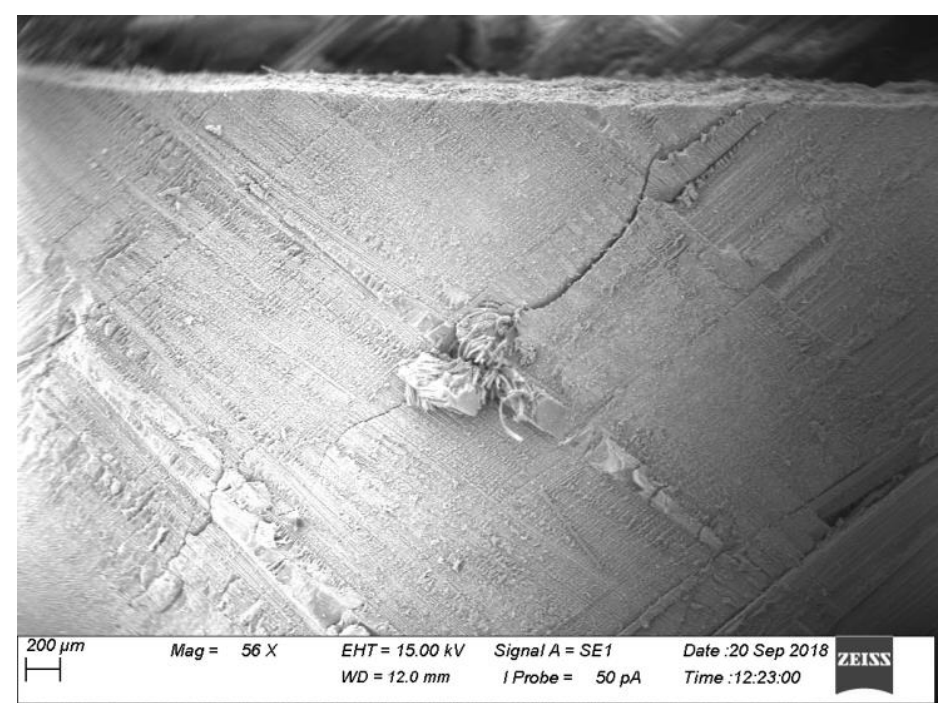

(b)

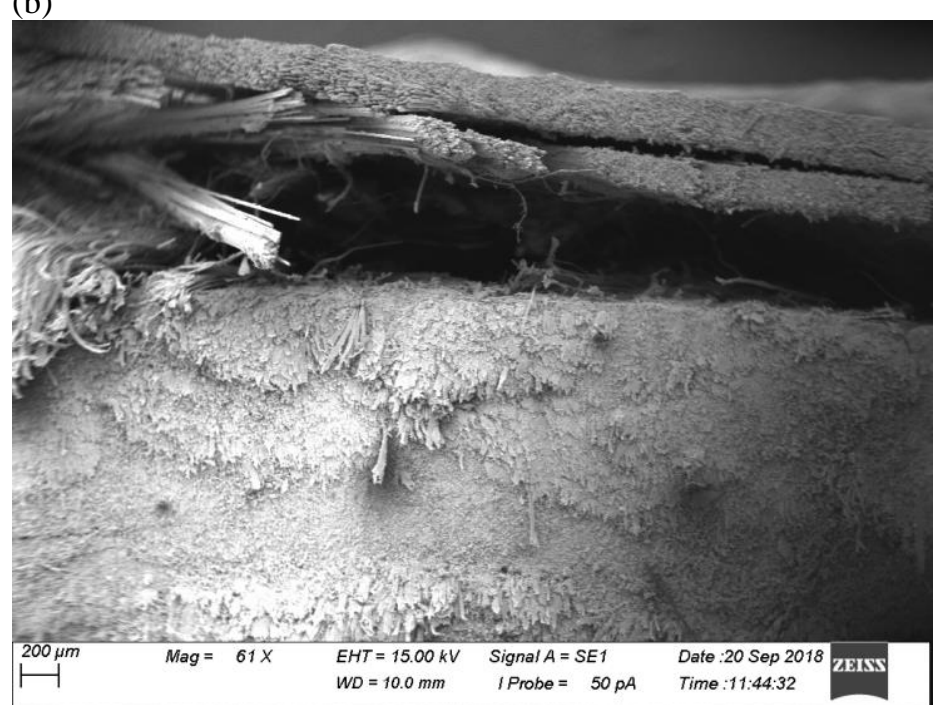

(d) 